\title{
Kejadian Menorrhagi pada Akseptor KB IUD Di BPS “SM” Manyar Gresik
}

\author{
Sulastri ${ }^{1}$ \\ Akademi Kebidanan Delima Persada Gresik, Indonesia ${ }^{1}$ \\ e-mail:sulastri.mkes@gmail.com
}

\begin{abstract}
Family planning is an effort to regulate the distance of pregnancy and improve family welfare. IUD contraceptive method is a non hormonal contraceptive method whose failure rate is relatively small and has long-term protection. But this method of contraception has several side effects. The purpose of this study is to examine the incidence of Menorrhagi in acceptors of IUD KB. This cross sectional descriptive survey design study was conducted at BPS "SM" Manyar Gresik with a population of 83 people. The sampling technique uses simple random sampling with a sample size of 68 people. Data was collected using observation sheets and questionnaires. Data were analyzed descriptively. The results showed that $22 \%$ of KB acceptors used IUD KB and 78\% used other methods. Menorrhagi in IUD acceptors reached $66.7 \%$. Regarding the high incidence of Menorrhagi for IUD KB acceptors, it is necessary to do KB and IEC Counseling on prospective IUD KB acceptors and how to overcome problems related to the side effects of using the IUD contraception method.
\end{abstract}

Keywords: family planning acceptors, IUD, menorrhagi

\section{Pendahuluan}

KB IUD merupakan metode kontrasepsi yang praktis paling sering digunakan di seluruh dunia dengan pemakai saat ini mencapai sekitar 100 juta wanita. Menurut pemakaian di dunia, China adalah negara pengguna AKDR terbesar di dunia, yakni $70 \%$ dari seluruh pengguna AKDR (Siswosudarmo, 2007). Meskipun memiliki efektifitas yang tinggi, KB IUD memilik beberapa efek samping.

Efek samping sering diartikan sebagai reaksi yang tidak dikehendaki yang terjadi karena pemakaian alat, sedang komplikasi diartikan sebagai akibat pemasangan. Salah satu efek samping KB IUD yaitu perdarahan haid banyak/menorrhagi (Saifuddin, 2006). Menorrhagi menyebabkan perdarahan menstruasi yang lebih besar dari 5 sendok makan per bulan.

Kondisi ini terjadi pada kira-kira $10 \%$ dari wanita. Penyebab Menorrhagi yaitu ketidakseimbangan hormon, Disfungsi ovarium, Uterine fibroids, Polip, Adenomyosi, IUD, Komplikasi kehamilan, gangguan perdarahan bawaan, obat-obatan, dan kondisi medis lain (Wiknjosastro, $\mathrm{H}$, 2009 dan Kompas, 2012).

Data yang didapat dari kantor KB dan Pemberdayaan Perempuan pencapaian peserta KB aktif Kabupaten Gresik sampai dengan bulan Desember tahun 2014 jumlah pasangan usia subur sebanyak 297.080 orang dan jumlah peserta KB aktif sebanyak 30.570 orang.

Diantaranya yang memakai kontrasepsi IUD sebanyak 1.838 orang $(6,01 \%)$, MOP 40 orang $(0,13 \%)$, MOW 368 orang $(1,20 \%)$, Implant 2.408 orang $(7,877 \%)$, Suntik 18.375 orang $(60,11 \%)$, Pil 6.491 orang $(21,23 \%)$, Kondom sebanyak 1.050 orang $(3,43 \%)$.

Survey awal di BPS "SM" Tanggul Rejo Manyar Gresik pada bulan Februari tahun 2015 diketahui jumlah PUS sebanyak 347 orang dan jumlah akseptor KB aktif yang berkunjung pada bulan Februari sebanyak 83 orang. Diantaranya yang memakai KB IUD sebanyak 15 orang $(18,07 \%)$, MOP (0\%), MOW sebanyak 2 orang $(2,41 \%)$, Implant sebanyak 3 orang $(3,61 \%)$, suntik sebanyak 28 orang $(33,73 \%)$, Pil sebanyak 35 orang $(42,17 \%)$ dan kondom $(0 \%)$.

Dari survey awal yang diambil dari 10 orang responden akseptor $\mathrm{KB}$ aktif, diketahui $30 \%$ akseptor KB non IUD tidak ada yang mengalami kejadian menorrhagi, $50 \%$ responden KB IUD mengalami kejadian perdarahan haid banyak (menorrhagi) dan $20 \%$ mengalami efek samping yang lain. Perdarahan sebagai efek samping penggunaan metode kontrasepsi 
sering menjadi penyebab klien menghentikan pemakaian KB (drop out), selain itu juga bisa menjadi faktor risiko kejadian anemia pada WUS. Bertambahnya volume dan lamanya perdarahan haid merupakan mekanisme timbulnya infeksi karena darah merupakan media subur untuk berkembang-biaknya kuman-kuman (Hartanto, 2010).

Penanganan terkait kejadian menorrhagi serta KIE merupakan hal yang penting untuk memastikan bahwa seorang WUS siap menghadapi kemungkinan perubahan pola haid dengan pemakaian AKDR (Pendit, 2007). Berdasarkan urain yang telah dipaparkan maka perlu dilakukan pengkajian terkait kejadian Menorrhagi di BPS "SM" Manyar Gresik.

\section{Metode}

\subsection{Metode Pengumpulan Data}

Penelitian survey deskriptif dengan pendekatan cross sectional di lakukan di BPS "SM" Manyar Gresik. Variabel dalam penelitian ini yaitu kejadian menorrhagi pada akseptor KB IUD. Populasi yang diambil yaitu semua peserta KB aktif yang berkunjung pada Bulan februari 2015 sebanyak 83 orang.

Sampel yang di ambil sebesar 68 orang yang diambil dengan teknik simple random sampling, dengan kriteria sampel sebagai berikut : Akseptor KB aktif yang bersedia menjadi responden penelitian. Teknik pengumpulan data dilakukan menggunakan teknik observasi (pengamatan), observasi dilakukan dengan cara mengamati jumlah perdarahan yang keluar dengan membandingkan dengan gambar yang terdapat pada pedoman observasi, selain itu juga dilakukan wawancara secara langsung pada responden dan pengumpulan data sekunder dengan melihat data rekam medis.

\subsection{Metode Analisis Data}

Data yang terkumpul di analisis secara univariate (deskriptif) menggunakan program SPSS 21.

\section{Hasil dan pembahasan}

Hasil penelitian menguraikan
tentang data umum yang meliputi

karakteristik responden dan data khusus.

1. Umur

Dari hasil penelitian diperoleh distribusi responden berdasarkan umur sebagaimana pada tabel 1 .

Tabel 1 Distribusi responden berdasarkan umur di BPS "SM" Tahun 2015

\begin{tabular}{llcc}
\hline No & $\begin{array}{l}\text { Umur } \\
\text { (Tahun) }\end{array}$ & $\begin{array}{c}\text { Frekuensi } \\
\text { (f) }\end{array}$ & $\begin{array}{c}\text { Persentase } \\
(\%)\end{array}$ \\
\hline 1 & $<20$ & 10 & 15 \\
2 & $20-30$ & 34 & 50 \\
3 & $30-40$ & 15 & 22 \\
4 & $>40$ & 9 & 13 \\
\hline & Total & 68 & 100 \\
\hline
\end{tabular}

Tabel 1 menunjukkan bahwa sebagian besar responden berusia 20-30 tahun $(50 \%)$ dan sebagian kecil berusia $>$ 40 tahun (13\%).

2. Jumlah anak

Dari hasil penelitian diperoleh distribusi responden berdasarkan jumlah anak sebagaimana pada tabel dibawah 2 .

Tabel 2 Distribusi responden berdasarkan jumlah anak di BPS "SM" Tahun 2015

\begin{tabular}{lccc}
\hline No & $\begin{array}{c}\text { Jumlah } \\
\text { anak }\end{array}$ & Frekuensi & $\begin{array}{c}\text { Persentase } \\
(\%)\end{array}$ \\
\hline 1 & 1 & 27 & 40 \\
2 & 2 & 25 & 37 \\
3 & 3 & 10 & 15 \\
4 & $>3$ & 6 & 9 \\
\hline & Jumlah & 68 & 100 \\
\hline
\end{tabular}

Tabel 2 menunjukkan bahwa sebagian besar responden memiliki anak 1 $(40 \%)$ dan sebagaian kecil mempunyai jumlah anak $>3(9 \%)$.

3. Pendidikan

Dari hasil penelitian diperoleh distribusi responden berdasarkan pendidikan sebagaimana pada tabel 3 . 
Tabel 3 Distribusi responden berdasarkan pendidikan di BPS "SM" Tahun 2015

\begin{tabular}{llcc}
\hline No & Pendidikan & Frekuensi & $\begin{array}{c}\text { Prosentasi } \\
(\%)\end{array}$ \\
\hline 1 & SD & 5 & 7 \\
2 & SMP & 18 & 26 \\
3 & SMU & 43 & 63 \\
& Akademi & & \\
4 & PT & 2 & 3 \\
\hline & Total & 68 & 100 \\
\hline
\end{tabular}

Tabel 3 menunjukkan bahwa pendidikan responden sebagian besar adalah SMU (63\%) dan sebagian kecil berpendidikan akademik/PT (3\%).

\section{Pekerjaan}

Dari hasil penelitian diperoleh distribusi responden berdasarkan pekerjaan sebagaimana pada tabel 4 .

Tabel 4 Distribusi responden berdasarkan pekerjaan di BPS "SM" Tahun 2015

\begin{tabular}{llcc} 
No & Pekerjaan & Frekuensi & $\begin{array}{c}\text { Prosentasi } \\
(\%)\end{array}$ \\
\hline 1 & PNS & 1 & 1 \\
2 & Wiraswasta & 37 & 54 \\
3 & Swasta & 8 & 12 \\
4 & Tidak Bekerja & 22 & 32 \\
\hline & Total & 68 & 100 \\
\hline
\end{tabular}

Tabel 4 menunjukkan bahwa pekerjaan responden sebagian besar adalah Wiraswasta ( $54 \%$ ) dan sebagian kecil bekerja sebagai PNS (1\%).

\section{Keikutsertaan KB IUD}

Dari hasil penelitian diperoleh distribusi responden berdasarkan akseptor KB sebagaimana pada tabel 5 .

Tabel 5 Distribusi Keikutsertaan KB di BPS "SM" Tahun 2015

\begin{tabular}{lcc}
\hline Jenis KB & Frekuensi & $\begin{array}{c}\text { Prosentasi } \\
(\mathbf{\%})\end{array}$ \\
\hline Non KB IUD & 53 & 78 \\
KB IUD & 15 & 22 \\
\hline Jumlah & 68 & 100
\end{tabular}

Tabel 5 menunjukkan sebagian besar responden menggunakan metode kontrasepsi non KB IUD.
6. Kejadian Menorrhagi

Dari hasil penelitian diperoleh distribusi responden berdasarkan kejadian Menorrhagi sebagaimana pada tabel 6 dan 7.

Tabel 6 Kejadian Menorrhagi Pada Akseptor KB di BPS "SM" Tahun 2015

\begin{tabular}{llc}
\hline $\begin{array}{l}\text { Kejadian } \\
\text { Menorrhagi }\end{array}$ & Frekuensi & $\begin{array}{c}\text { Prosentasi } \\
(\%)\end{array}$ \\
\hline Tidak & 56 & $82 \%$ \\
Ya & 12 & $18 \%$ \\
\hline Jumlah & 68 & $100 \%$ \\
\hline
\end{tabular}

Tabel 6 menunjukkan $18 \%$ responden mengalami kejadian Menorrhagi, dan sebagian besar responden yang tidak mengalami kejadian Menorrhagi $(82 \%)$.

Tabel 7 Kejadian Menorrhagi Pada Akseptor

\begin{tabular}{cllc}
\multicolumn{4}{c}{ KB IUD di BPS "SM" } \\
\hline $\begin{array}{l}\text { Metode } \\
\text { Kontrasepsi }\end{array}$ & $\begin{array}{l}\text { Kejadian } \\
\text { Menorrhagi }\end{array}$ & F & \% \\
\hline & Ya & 8 & 66,7 \\
\multicolumn{1}{c}{ IUD } & Tidak & 4 & 33,3 \\
\hline Jumlah & & 12 & 100 \\
\hline
\end{tabular}

Tabel 7 menunjukkan sebagian besar akseptor KB IUD mengalami efek samping menorrhagi $(66,7 \%)$.

Sebagian kecil ibu menggunakan metode kontrasepsi IUD. Menurut Pendit (2007) AKDR adalah suatu alat plastik atau logam kecil yang dimasukkan ke uterus melalui kanalis servikalis. Keikutsertaan penggunaan kontrasepsi dipengaruhi oleh beberapa faktor diantaranya kepentingan pribadi, pertimbangan kesehatan, faktor ekonomi, faktor budaya dan pengetahuan.

Dilihat berdasarkan tingkat pengetahuan, sebagian besar ibu mempunyai tingkat pendidikan menengah (SMU), hal ini juga bisa menjadi penyebab kurangnya minat ibu untuk menjadi akseptor KB IUD. Pengetahuan seseorang dipengaruhi oleh banyak hal diantaranya karena umur, pendidikan, pekerjaan, minat, pengalaman, kebudayaan lingkungan sekitar dan informasi (Handayani, S. 2010).

Berdasarkan pekerjaan, mayoritas masyarakat bekerja sebagai wiraswasta 
dengan sosial ekonomi menengah kebawah, berdasarkan hasil wawancara diketahui ibu kurang berminat menggunakan KB IUD karena takut dengan proses pemasangan dan pencabutan, ibu menyampaikan bahwa penggunaan KB IUD akan memerlukan pembedahan. Selain itu karena terkait dengan ekonomi menengah ke bawah, ibu baru akan mengikuti program keluarga berencana kalau sudah ada safari $\mathrm{KB}$ dengan alasan karena tidak mengeluarkan biaya.

Dari urian dan fakta yang ada maka diperlukan kerjasama yang baik antara petugas kesehatan, aparat desa dan para kader dalam memberikan informasi tentang $\mathrm{KB}$, penyelenggaraan safari $\mathrm{KB}$ secara reguler, pemberian informasi tentang penggunaan asuransi kesehatan non premi untuk masyarakat tidak mampu.

Disamping itu ketersediaan fasilitas, sikap, dan perilaku petugas kesehatan khususnya bidan terhadap masyarakat juga akan mendukung dalam penggunaan alat kontrasepsi terutama $\mathrm{KB}$ IUD. Sehingga akan mendorong akseptor untuk melakukan sesuatu yang mereka inginkan termasuk keinginan dalam menggunakan alat kontrasepsi yang sesuai dengan kebutuhan dan keinginan mereka.

Hasil penelitian menunjukkan prosentase dari seluruh akseptor $\mathrm{KB}$, hanya $18 \%$ pasein yang mengalami efeksamping Menorrhagi. Namun 66,7\% akseptor KB IUD mengalami efek samping Menorrhagi. Perdarahan vagina yang sangat berat/parah, disebut menorrhagi yaitu volume darah haid bertambah rata-rata $50-100 \%$ di atas volume pra-insersi (Saifuddin, 2006). Penyebab Menorrhagi yaitu ketidakseimbangan hormon, Disfungsi ovarium, Uterine fibroids, Polip, Adenomyosi, IUD, Komplikasi kehamilan, gangguan perdarahan bawaan, obat-obatan, Kondisi medis lain (Kompas, 2015).

Berdasarkan hasil penelitian bahwa angka kejadian menorrhagi akseptor $\mathrm{KB}$ IUD menunjukkan prosentasi yang relatif tinggi, hasil wawancara menunjukkan bahwa ibu pengguna KB IUD sebagian besar kurang memahami tentang efek samping yang mungkin terjadi pada pemakai alat kontrasepsi KB IUD.
Efek samping yang berupa
perdarahan menghentikan pemakaian KB IUD dan hal ini juga menjadi resiko kesehatan bagi pemakai dikhawatirkan terjadi anemia. Bertambahnya volume dan lamanya perdarahan haid merupakan mekanisme timbulnya infeksi karena darah merupakan media subur untuk berkembang-biaknya kuman-kuman (Hartanto, 2010).

Dari kenyataan diatas diperlukan KIE mengenai efek samping KB untuk memastikan bahwa wanita yang bersangkutan siap menghadapi kemungkinan perubahan pola haid. Informasi tentang efek samping dan komplikasi yang mungkin terjadi serta cara menangani keluhan harus di sampaikan kepada calon akseptor KB. Hal ini dilakukan untuk menghindari perasaan cemas dan khawatir serta pemberian jaminan rasa nyaman pada akseptor KB IUD.

\section{Simpulan dan Saran \\ 4.1 Simpulan}

Sebagian besar ibu akseptor KB IUD

di BPS "SM" mengalami Menorrhagi $(66,7 \%)$.

\subsection{Saran}

Saran dari hasil penelitian ini adalah dibutuhkan peran serta tenaga kesehatan terutama bidan dalam meningkatkan mutu pelayanan terutama pelayanan kontrasepsi yang bermutu tinggi agar derajat kesehatan masyarakat dapat meningkat, usaha yang bisa dilakukan adalah dengan memberikan KIE secara berkesinambungan dan KIPK dengan tepat diantara penyuluhan yang dapat diberikan yaitu tentang pengertian KB IUD, kemungkinan-kemungkinan efek samping dan komplikasi yang akan terjadi dan cara mengatasi keluhannya terutama efek sampig KB IUD tentang kejadian menorrhagi serta memberikan obat-obatan agar tidak sampai terjadi anemia. 


\section{Daftar Pustaka}

Handayani, Sri. (2010). Buku Ajar Pelayanan Keluarga Berencana. Jogjakarta : Pustaka Rihama.

Hartanto, Hanafi. (2010). Keluarga berencana dan kontrasepsi. Jakarta: Pustaka Sinar Harapan.

Manuaba, dkk. (2010). Ilmu Kebidanan, Penyakit Kandungan dan KB untuk Pendidikan Bidan. Jakarta : EGC.

Mansjoer, Arif. (2001). Kapita selesakta kedokteran. Medika Aescalapius.

Pendit. (2007). Ragam metode kontrasepsi. Jakarta : Buku kedokteran EGC.

Saifuddin, Abdul Bari. (2006). Panduan Praktis Pelayanan Kontrasepsi. Jakarta : Yayasan Bina Pustaka Sarwono Prawiroharjo.

Siswosudarmo, dkk. (2007). Teknologi Kontrasepsi. Yogyakarta : Gadja Madah University Press.

Wiknjosastro, Hanifa. (2009). Ilmu Kandungan. Jakarta: PT Bina Pustaka Sarwono Prawirohardjo.

Kompas. (2012). Menorragi. (http://health.kompas.com/direktori yourbody/84/Menorrhagi), retrieved tanggal 12 September 2015. 